\title{
The Evaluation of Financing Efficiency of China's Stock Market
}

\author{
Ji-chang Dong, Lin-lin Zhu, Bing Wang, Zhi Dong, and Xiu-ting Li \\ School of Economics and Management, University of Chinese Academy of Sciences, Beijing 100190, China \\ Correspondence should be addressed to Xiu-ting Li; lindaall@163.com
}

Received 11 March 2016; Revised 23 June 2016; Accepted 12 July 2016

Academic Editor: Xiaodong Lin

Copyright (C) 2016 Ji-chang Dong et al. This is an open access article distributed under the Creative Commons Attribution License, which permits unrestricted use, distribution, and reproduction in any medium, provided the original work is properly cited.

\begin{abstract}
Financing is the main way for listed companies to obtain funds in China, and it is the "reservoir" which can guarantee enterprises to operate continuously. Financing efficiency can be used to measure the efficiency in using enterprises' own funds, and it is one of the main indicators which are concerned by the stakeholders of listed companies. This paper mainly researches on the impact of equity financing on the financing efficiency of listed companies as a whole and selects 300 listed companies in the Shanghai and Shenzhen Stock Exchange as decision-making units. Then this paper analyzes the financial data of sample companies in 2008-2014. Finally, it can be concluded that the financing efficiency of listed companies in China is generally low, and the total factor productivity in the stock market continued to decline between 2003 and 2005 and then rose rapidly.
\end{abstract}

\section{Introduction}

Capital is the main driving force for the companies to maintain the operation, a large number of money and sustained cash flow can guarantee the development of the enterprises. Because cash has strong liquidity, it can be used to meet the needs of the daily production and business activities of the enterprises and it also can be used to repay the debt, shortterm investment, and technology research. With enough money, companies have a strong ability to resist risks. At present, the main financing channels of the enterprises in China are equity financing and bond financing. So far, our stock market has developed for more than 20 years. Although in these 20 years, the equity financing has experienced a lot of twists and turns, China's listed companies get a lot of money from the stock market to meet the needs of development. Therefore, equity financing has become the main financing channels of China's listed companies.

As the main form of company, listed companies have played an important role in the economic and social development of a country. In our country, the listed companies are the main force of national economy, the important sources of national wealth, and the engine of industrial transformation and upgrading. Meanwhile, they also play an increasingly vital role in expanding employment, meeting the diverse and individual needs of residents, achieving social specialization and collaboration, nurturing entrepreneurs, and technological innovation. As a result of better prospects for development, more and more investors choose to invest in listed companies. However, in the face of the increasingly competitive international economic environment, the risk faced by the listed companies becomes diversified, leading the shareholders to begin to pay attention to the efficiency in using funds of the invested companies. Therefore, in our country, under the condition of severe financial constraints, how to choose appropriate financing way and the proportion and form a reasonable financing structure and achieve higher efficiency in using funds and profit rate under the limited funds supply will become the main problem of the listed companies.

\section{Literature Review}

Financing efficiency, which has been widely concerned by scholars at home and abroad, is the core issue of enterprise development. Stulz believes that the transparency of financial information has an impact on the level of financing efficiency. When the information is not sufficient, In order to avoid taking risks, investors tend to miss the good investment projects, leading to the low financing efficiency [1]. SchmidtMohr believes that the corporate governance structure is the main factor that affects the financing efficiency of companies, and the reasonable corporate governance structure can 
improve the financing efficiency [2]. From the perspective of the financing structure, Chamberlain studied the financing efficiency of American listed companies and obtained that the companies which have higher equity financing have a lower financing efficiency. Only when the structure of the investment and financing of companies reached a reasonable proportion, the financing efficiency would be improved [3]. Romano et al. pointed out that the enterprise scale, business plan, and business goals will affect the debt level of companies, affecting companies' financing decision and financing efficiency [4]. Sulla et al. studied the financing mode of the small and medium enterprises in Eastern Europe and concluded that the financing constraints are the main factors that affect the long-term financing efficiency of small and medium enterprises [5]. Cardone et al. believed that because of the defects of small and medium-sized enterprises, it is difficult to obtain funds from the capital market. Therefore, through changing the direction of financing, turning to the credit market, and obtaining funds by providing service guarantee, the financing efficiency of small and medium enterprises can be improved [6].

Chinese scholar Kangling points out that the main factors which affect the financing efficiency include interest mechanism, information sensitive and fidelity, the degree of risk investment, monetary policy, and the market maturity and uses comparative analysis to analyze the efficiency and cost of enterprise direct financing and indirect financing [7]. Wenbing points out that the financing efficiency includes two aspects of transaction efficiency and allocative efficiency and concludes that the financing efficiency of equity financing is lower than that of financing with banks as intermediaries [8]. Haihong and Minghua argue that financing scale, financing channels, and the way of financing are the main factors affecting financing efficiency of enterprises $[9,10]$. Xinlan and Lianqin argue that enterprise financing efficiency refers to the ability of enterprises to bring and use the funds to create value for the enterprises. Therefore, the financing efficiency of enterprises can be divided into the transaction efficiency and the efficiency in using funds in accordance with the costs and benefits [11]. Quanxing believes that the financing efficiency refers to the efficiency achieved in the daily financing activities of the companies; he believes that the financing efficiency can be divided into macro financing efficiency and micro financing efficiency. Micro financing efficiency includes the financing contract governance efficiency and financing policy selection efficiency; macro efficiency refers to the allocation efficiency of social total resources which are guided by listing Corporations through individual financing [12].

\section{Model Analysis}

3.1. The Choice of Evaluation Methods. At present, domestic and foreign scholars mainly use DEA model to measure the financing efficiency of the listed companies. In 1985, Schmalensee uses American manufacturing enterprises as the research object and uses the return on assets (ROA) as an indicator to measure of corporate performance. Rajan and Zingales use financial data of listed companies in the United States from 1984 to 1986 as the research object, and using the DEA model they conclude that the majority of enterprise external financing is debt financing [13]. Lichang selects 47 companies listed in Shanghai at the beginning of 1998 as the research sample and uses Data Envelopment Analysis (DEA) method to evaluate the efficiency of equity financing in China. Using the amount of equity financing, ownership concentration, nonliquidity of stock, and assetliability ratio as input indicators and the rate of return on net assets, main business revenue growth rate, and Tobin $Q$ value as the output indicators, he concludes that the equity financing efficiency of China's listed companies is generally low. Among them, the information technology industry has higher allocation efficiency and public utilities and health care industry have lower allocation efficiency [14]. From macro perspective, Xiaowen regards the number of listed companies, the size of the stock issuance, and stock trading volume as input indicators and gross domestic product (GDP) as output indicators and uses the Data Envelopment Analysis (DEA) model to analyze the financing efficiency of the BRICs stock market [15]. Xiaobo selected some relatively representative listed companies of China and India and uses total assets, asset-liability ratio, and ownership concentration as input indicators of DEA and rate of return on common stockholders' equity, earnings per share, and increase amount of business revenue as the output indicators to analyze the equity financing efficiency of the two countries' stock market from the three angles of technical efficiency, pure technical efficiency, and scale efficiency and puts forward relevant policy suggestions [16].

Based on Farrell [17] technical efficiency, DEA (Data Envelopment Analysis) model was first proposed by Charnes, Cooper, and Rhods in 1978. The model uses the input and output of the decision unit to establish the corresponding optimal boundary to measure the efficiency. Due to the fact that DEA model does not need to set up the input-output function of decision unit and also does not need to regard the weights of input and output as variables, therefore, it can be simply and quickly used to evaluate the efficiency of social organizations and enterprises. The analysis results of this model are more ideal when the two variables are "technology efficient" and "scale efficient" at the same time. And this model optimizes each decision-making unit, and through optimizing the lack of the final mining relevant index, it can automatically adjust the lack. Therefore, it evaluates based on the advantage of decision-making units. So far, DEA model has become one of the main tools of efficiency evaluation. Therefore, this paper will randomly select the companies listed in China as the research sample, use the indicators most obvious impact on the financing efficiency as the input and output indicators of DEA model, evaluate the financing efficiency of China's stock market in the period of economic transition, and explore ways to improve the equity financing efficiency of China's listed companies.

3.2. Introduction of Model. Assume that there are $n$ decisionmaking units (DMUs), and each DMU has an input vector $\mathbf{X}=\left(x_{1}, x_{2}, \ldots, x_{m}\right)^{T}$ and output vector $\mathbf{Y}=\left(y_{1}, y_{2}, \ldots, y_{s}\right)^{T}$. For any decision-making unit, $\mathrm{DMU}_{j}$ has production possibility set based on the axiom of convexity hypothesis, cone 
hypothesis, inefficiency hypothesis, and minimal hypothesis:

$$
\begin{aligned}
T & =\left\{(X, Y) \mid \sum_{j=1}^{n} X_{j} \lambda_{j} \leq X, \sum_{j=1}^{n} Y_{j} \lambda_{j} \geq Y, \lambda_{j} \geq 0, j\right. \\
& =1,2, \ldots, n\} .
\end{aligned}
$$

And it has obtained the following DEA model $\left(C^{2} R\right)$ :

$$
\begin{array}{ll}
\min & {\left[\theta-X\left(\sum_{i=1}^{m} s_{i}^{-}+\sum_{r=1}^{s} s_{r}^{+}\right)\right],} \\
\text {s.t. } & \sum_{j=1}^{n} x_{i j} \lambda_{j}+s_{i}^{-}=\theta x_{i j_{0}}, \quad i \in(1,2, \ldots, m), \\
& \sum_{j=1}^{n} y_{r j} \lambda_{j}-s_{r}^{+}=y_{r j_{0}}, \quad r \in(1,2, \ldots, s), \\
& \theta, \lambda_{j}, s_{i}^{-}, s_{r}^{+} \geq 0, \quad j=1,2, \ldots, n .
\end{array}
$$

In the above formula,

(1) if $\theta^{*}=1, s^{-^{*}}=0, s^{+^{*}}=0$, it is said that the decisionmaking unit $j_{0}$ is effective;

(2) if $\theta^{*}<1$, or $s^{-^{*}} \neq 0, s^{+^{*}} \neq 0$, it is said that the decision-making unit $j_{0}$ is not effective.

The coefficient of $\theta$ can be understood as a "compression coefficient" of decision-making unit $\left(\mathrm{DMU}_{j_{0}}\right)$ 's input vector. If $\theta^{*}=1, s^{-^{*}}=0, s^{+^{*}}=0$, then the decision-making unit not only has the same scale of income, but also has the best technical efficiency. It means that the input cannot be compressed in equal proportions, and there is no "excessive" input and "deficient" output. Then the decision-making unit is in the effective situation, namely, DEA effective. If $\theta^{*}<1$, or $s^{-^{*}} \neq 0, s^{+^{*}} \neq 0$, it indicates that the decision-making unit cannot meet the same scale of income and best technical efficiency at the same time. Then certain aspects of the input are still "excessive" or some outputs are "deficient." It means that the decision-making unit is not in the effective situation, namely, DEA ineffective. If $0<\theta^{*}<1$, the input of the decision-making unit is improper, namely, DEA ineffective.

And, $m$ and $s$ indicate the number of input and output indicators, respectively; $x_{i j_{0}}$ and $y_{r j_{0}}$ represent the $i$ th input and the $r$ th output of $j_{0}$ th DMU; $s_{r}^{+}$and $s_{i}^{-}$are slack variables, respectively; $X$ is the non-Archimedes infinitesimal. In the calculations, we give it an infinitesimal number, such as $X=$ $10^{-6}$.

In addition, with the help of the projection on the relative effective surface of DEA, we can find out the improved way of input aspect when a non-DEA effective decision-making unit becomes DEA effective. Assume that $s_{i}^{-^{*}}, s_{r}^{+^{*}}, \theta^{*}$ are the optimal solution of decision-making unit $j_{0}$ in the $C^{2} R$ model, if $\hat{x}_{i j_{0}}=\theta^{*} x_{i j_{0}^{-}}-s_{i}^{-*}, \hat{y}_{r j_{0}}=y_{r j_{0}^{-}}+s_{r}^{+^{*}}$, then $\left(\widehat{x}_{i j_{0}}, \widehat{y}_{r j_{0}}\right)$ is the projection of $\mathrm{DUM}_{j_{0}}$ on the relative effective surface of DEA which is corresponding to $\left(x_{0}, y_{0}\right)$. It means that $\left(\widehat{x}_{i j_{0}}, \widehat{y}_{r j_{0}}\right)$ lands on the outer surface of the production possibility set (production frontier) consisted by $\left(x_{0}, y_{0}\right)$. From this, we can find out the gap between each indicator and the relative effective goal when a decision-making unit becomes DEA effective.

\subsection{Construction of Evaluation Index System}

3.3.1. Selection of Decision Unit. In order to make the measurement and the evaluation results of the financing efficiency of listed companies more accurate and reliable and to ensure the representatives of sample companies and the reliability and effectiveness of data, this paper selects 300 companies listed in Shenzhen and Shanghai Stock Exchange as decisionmaking unit and uses the financial data of the sample enterprise from 2008 to 2014 to study the financing efficiency of listed companies in our country. The 300 listed companies selected in this paper cover most industries in our country, the sample selection of the existing literatures research on the financing efficiency is restricted to a particular industry or region, at this point, and the selected samples in this paper are more representative and inclusive. As part of the stock data of listed companies is missing, therefore, this paper chooses 220 listed companies as decision-making units; the data comes from the financial report of sample companies and the Wind database. In order to apply DEA analysis, the number of samples of a decision-making unit has to be at least twice the sum of input and output indicators, while in the present paper the number of samples of a decision-making unit is 220 and the sum of input and output indicators is 5, which is in line with the application experience rule of DEA model.

3.3.2. The Influence Factors of the Financing Efficiency. Xiaojun et al. point out that the equity financing efficiency of enterprises includes two aspects, namely, whether the listed companies can obtain needed funds with the lowest cost and whether the equity of listed companies can be optimally utilized. Only when the enterprise gains the maximum profit with the minimum financing cost, it has financing efficiency [18]. Therefore, financing income and financing cost are two main factors directly impacting on the financing efficiency evaluation. The financing efficiency of enterprises as the performance in the process of financing can be investigated from two aspects of the income and cost of different financing modes.

\section{(A) Financing Cost Category}

(1) Financing Cost. Financing cost is the price of financing and the use of funds and should not be less than the expected rate of return of capital. It also has important reference value for enterprises to choose the mode and the number of financing. The cost of capital is inversely proportional to financing efficiency; the higher the capital cost is, the lower the financing efficiency becomes. The financing efficiency can reflect whether the company can bring as much needed 
fund as possible at as much lower cost as possible, which includes the ability of making the lowest cost choice among a variety of financing methods and whether they can raise sufficient needed funds timely. Because the supply of financing way is determined by the market and other external conditions, within a certain period of time, the minimum income required by investors is also determined by the market and the lowest price for enterprises to obtain capital depends largely on the degree of risk of different financing ways.

(2) Financing Risk. The risk caused by financing is another form of cost. The financing risk refers to the additional risk bearded by the owners caused by the uncertainty of the rate of return on capital and loan interest. It includes the risk when corporate has lost the ability to repay the debt and when enterprise shareholders suffer losses caused by debt. So, the business owners should maintain control over the enterprises as far as possible when raising funds. The loss of control and ownership of enterprises will affect the independence and autonomy of the production and operation of enterprises, distracts the profits of enterprises, which leads the interests of shareholders to suffer losses, and hinders the development of enterprise in the long run. External financing will be restricted by the laws, regulations, system, and other factors, different financing ways have different financing risks; the financing risk is inversely proportional to financing efficiency.

(3) The Degree of Freedom of the Use of Funds. In different ways of financing, enterprises have different rights to control the capital. The enterprises' financing capacity, financing way, and financing whereabouts, namely, whether the limited resources are allocated to these enterprises or departments who have higher output and contribute to the economic development can not only improve the allocation efficiency of social resources, but also stimulate the departments who have low efficiency to improve efficiency. Otherwise, they will be eliminated because of funding fracture. In this way, through the movement of funds and in the process of realizing the maximization of their own interests, individual enterprises can achieve the optimal allocation of social resources and the improvement of economic efficiency. As the user of capital, when the enterprises raise funds in different ways, they will face different external pressures and the degree of constraints. The more the conditions attached in the process of using funds, the lower the degree of freedom in the process of using funds. Under the restraint condition, if funds cannot be invested to the projects that have the highest return, or because the degree of freedom in the process of using funds is restricted, the enthusiasm of enterprise operators is affected and the enterprises cannot generate the highest revenue; then the financing efficiency is undoubtedly low. The agency cost arising from the conflict of interests between the subjects of financing and capital providers also affect the financing efficiency. Therefore, the higher the degree of freedom in the process of using funds, the higher the efficiency of financing and, conversely, the lower the efficiency of financing.

\section{(B) Financing Income Category}

(1) The Utilization Rate of Capital. The evaluation indexes of financing efficiency should also reflect whether the operation efficiency of enterprises has been improved in a certain time span after obtaining funds. The operation efficiency of enterprises directly determines the ability of the enterprise to make the assets into profit and cash. Under the condition of obtaining financial support, if the enterprise improves operating efficiency through financing activities, the cash payment ability will be enhanced, and ultimately the self-accumulation ability of enterprises will also be enhanced, which reflects the high financing efficiency of enterprise. If the enterprise's financing activity did not increase the operating efficiency, in other words, the efficiency in using funds of enterprise is very low, and thus the development capacity of the enterprise will not be enhanced, then the financing efficiency of enterprise is very low.

Therefore, the financing efficiency of enterprises mainly depends on whether the enterprise achieves the optimal use of limited resources. As four aspects of the theoretical framework to analyze the financing efficiency, the efficiency in using funds, financing cost, financing risk, and the degree of freedom of using funds plays crucial role on improving the financing efficiency.

3.3.3. The Construction of the Index System and the Choice of Sample Data. Selecting input and output indicators reasonably is a key step in the correct use of DEA model to evaluate the financing efficiency. Based on the preliminary analysis of the influence factors of the financing efficiency of enterprises and according to the characteristics of the financing efficiency of China's listed corporations, this paper design selects these following input and output indicators.

(A) Input Indicators. The principle of selecting input indicators is making sure that the input variables can reflect the enterprise's total amount of financing, financing structure, and the way of using funds. So, this paper takes the following three financial indicators as input variables.

(1) Equity Value. Equity value reflects the market value of the listed companies' raised funds through equity financing. It is constantly adjusted to reflect the book value and the change of the operating conditions of the market and the company. Hence it is objective and authentic.

(2) Ownership Concentration. Ownership concentration reflects the degree of the ownership structure of the listed companies on the financing efficiency; the higher the degree of ownership concentration, the stronger the ability of the listed company to make decisions, which is more conducive to make the correct investment decision and improve the financing efficiency. This paper uses the shareholding ratio of ten shareholders who have the highest shareholding ratio to express ownership concentration which is supposed by Xiaobo and Fan $[16,19]$. 


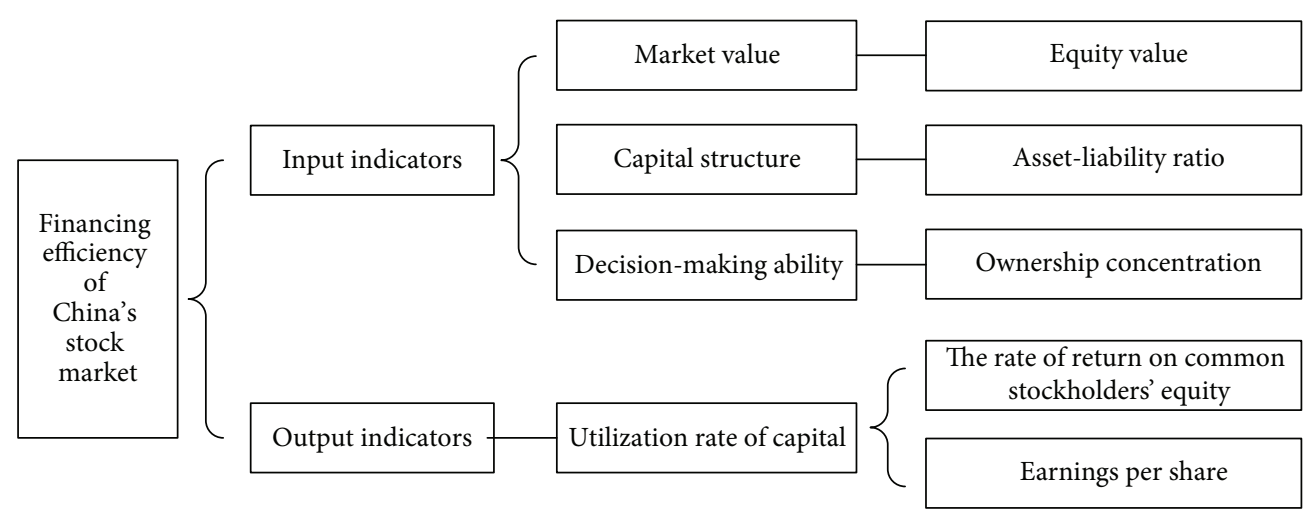

FIGURE 1: Evaluation index system diagram of enterprises' financing efficiency.

(3) Asset-Liability Ratio. Asset-liability ratio can reflect the rationality of the capital structure of the enterprise; using the financial leverage reasonably can bring financial leverage efficiency for the enterprise and get more substantial profits; using financial leverage excessively may lead the enterprise to have a greater financial risk and result in negative assets and other operating difficulties. Increase in the proportion of debt financing will reduce the external equity financing agency costs caused by conflict of interest between shareholders and managers, which can improve the equity financing efficiency of enterprises [20]. When equity financing accounted for more proportion of the total amount of financing, the financing efficiency of enterprises will decrease. Only when the financing structure of the enterprise is in accordance with a certain proportion, the financing efficiency of enterprises will reach the highest level [3]. Therefore, this paper will choose asset-liability ratio that reflects the capital structure as an input indicator to evaluate the financing efficiency of the enterprise.

(B) Output Indicators. The selection principle of output index is that the output variable must be able to reflect on the situation of using funds of the enterprise. Because the output variables of DEA model are the financing efficiency, this paper selects the rate of return on common stockholders' equity and the earnings per share as output variables. The growth rate of main business income is a direct index to measure the financing effect and reflects the level of financing efficiency. Rate of return on net assets reflects financing efficiency from the perspective of the application effect of capital.

(1) The Rate of Return on Common Stockholders' Equity. The index could in some extent reflect the application situation of capital coming from investors; the higher the rate of return on common stockholders' equity is, the higher the investment income becomes; the lower the rate of return on common stockholders' equity is, the weaker the profitability of business owners [21]. So, this paper selects the rate of return on common stockholders' equity as a financial efficiency indicator.
TABLE 1: Selection of the influence factors and indicators of the financing efficiency.

\begin{tabular}{|c|c|c|c|}
\hline & Category & Influence factors & Indicators \\
\hline \multirow{4}{*}{$\begin{array}{l}\text { Financing } \\
\text { efficiency of } \\
\text { enterprise }\end{array}$} & \multirow{3}{*}{ Cost } & Financing cost & Equity value \\
\hline & & Financing risk & Asset-liability ratio \\
\hline & & $\begin{array}{l}\text { The degree of } \\
\text { freedom of the } \\
\text { use of funds }\end{array}$ & $\begin{array}{l}\text { Ownership } \\
\text { concentration }\end{array}$ \\
\hline & Income & $\begin{array}{l}\text { The utilization } \\
\text { rate of capital }\end{array}$ & $\begin{array}{l}\text { The rate of return on } \\
\text { common } \\
\text { stockholders' equity, } \\
\text { earnings per share }\end{array}$ \\
\hline
\end{tabular}

(2) Earnings per Share. It is also called per share after tax profit or earnings per share; this index can measure the value of stock investment of the listed company and also is an important index to reflect the profitability of the listed company.

Through the above analysis, this paper chooses and classifies the influence factors and indicators of the financing efficiency as shown in Table 1.

From Table 1, we can draw the evaluation index system diagram of enterprises' financing efficiency as shown in Figure 1.

3.3.4. Correlation Test of the Model. When using DEA method to calculate the financing efficiency of enterprises, there should be irrelevance or weak relevance among input variables and output variables and there should be strong relevance between input variables and output variables. If the input variables and output variables are relevant, the results of DEA will not be correct, and we cannot effectively measure the financing efficiency of China's stock market. This paper uses SPSS software to calculate the correlation between 3 input indicators and 2 output indicators, as shown in Table 2.

It can be seen from Table 2 that the correlation coefficient between equity value and ownership concentration is 0.916 , the correlation coefficient between equity value and assetliability ratio is 0.887 , the correlation coefficient between 
TABLE 2: The correlation matrix of the input and output index.

\begin{tabular}{lccccc}
\hline & $\begin{array}{c}\text { Equity } \\
\text { value }\end{array}$ & $\begin{array}{c}\text { Ownership } \\
\text { concentration }\end{array}$ & $\begin{array}{c}\text { Asset-liability } \\
\text { ratio }\end{array}$ & $\begin{array}{c}\text { The rate of return on common Earnings per } \\
\text { stockholders' equity }\end{array}$ & $\begin{array}{c}\text { Ehare } \\
\text { share }\end{array}$ \\
\hline Equity value & 1 & 0.916 & 0.887 & 0.613 & 0.6852 \\
Ownership concentration & 0.916 & 1 & 0.8795 & 0.757 & 0.716 \\
Asset-liability ratio & 0.887 & 0.8795 & 1 & 0.764 & 1 \\
The rate of return on common stockholders' equity & 0.613 & 0.757 & 0.764 & 0.6827 \\
Earnings per share & 0.6852 & 0.716 & 0.6827 & 0.7702 & 1 \\
\hline
\end{tabular}

TABLE 3: The results of principal component analysis of input indicators.

\begin{tabular}{lccr}
\hline Indicators & \multicolumn{3}{c}{ Principal component } \\
\hline Equity value & 0.6453 & 0.6298 & 0.6665 \\
Ownership concentration & 0.5652 & 0.5691 & 0.5374 \\
Asset-liability ratio & 0.5139 & 0.5286 & 0.5167 \\
\hline
\end{tabular}

TABLE 4: The results of principal component analysis of output indicators.

\begin{tabular}{lcc}
\hline Indicators & \multicolumn{2}{c}{ Principal component } \\
\hline $\begin{array}{l}\text { The rate of return on common } \\
\text { stockholders' equity }\end{array}$ & 0.7071 & 0.7132 \\
Earnings per share & 0.7041 & 0.7009 \\
\hline
\end{tabular}

ownership concentration and asset-liability ratio is 0.8795 , and the correlation coefficient between asset-liability ratio and earnings per share is 0.7702 . Thus it can be seen that there is great correlation between the input and output indicators. At the same time, the correlation coefficients between equity value and the rate of return on common stockholders' equity and earnings per share are 0.613 and 0.6852 and the correlation coefficients between ownership concentration and the rate of return on common stockholders' equity and earnings per share are 0.764 and 0.6827 . Thus it can be seen that there is a significant positive correlation between the input and output indicators. Because the correlation between the input and output indicators will affect the analysis results, this paper will use principal component analysis to eliminate the correlation between the output indicators. The results of principal component analysis are shown in Tables 3 and 4 .

The principal components are $0.6453 *$ equity value + $0.5652 *$ ownership concentration $+0.5139 *$ asset-liability ratio, $0.6298 *$ equity value $+0.5691 *$ ownership concentration $+0.5286 *$ asset-liability ratio, $0.6665 *$ equity value + $0.5374 *$ ownership concentration $+0.5167 *$ asset-liability ratio, $0.7071 *$ the rate of return on common stockholders' equity $+0.7041 *$ earnings per share and $0.7132 *$ the rate of return on common stockholders' equity $+0.7009 *$ earnings per share; they are regarded as input and output indicators. The principal components are irrelevant or weakly relevant, using principal components as input variables and output variables will draw the correct and effective results.
TABLE 5: The grading standards of financing efficiency.

\begin{tabular}{lcccc}
\hline $\begin{array}{l}\text { Division of } \\
\text { financing } \\
\text { efficiency }\end{array}$ & 1 & $1-0.8$ & $0.8-0.5$ & $0.5-0$ \\
\hline $\begin{array}{l}\text { Level of } \\
\text { financing } \\
\text { efficiency }\end{array}$ & $\begin{array}{c}\text { The best } \\
\text { financing } \\
\text { efficiency } \\
\text { interval }\end{array}$ & $\begin{array}{c}\text { High } \\
\text { financing } \\
\text { efficiency } \\
\text { interval }\end{array}$ & $\begin{array}{c}\text { Relatively high } \\
\text { financing } \\
\text { efficiency } \\
\text { interval }\end{array}$ & $\begin{array}{c}\text { Low } \\
\text { financing } \\
\text { efficiency } \\
\text { interval }\end{array}$ \\
\hline
\end{tabular}

3.4. The Results of the Model. This paper will use DEAP 2.1 software to calculate the financing efficiency of China's listed companies. Compared with other software, this software can get the optimal solution and the relative efficiency value of the model; the efficiency values include the overall technical efficiency (CRSTE), pure technical efficiency (VRSTE), scale efficiency (scale), and returns to scale.

According to the different range of financing efficiency, financing efficiency of enterprises can be divided into four levels: the best financing efficiency, high financing efficiency, relatively high financing efficiency, and low financing efficiency, as shown in Table 5.

When the financing efficiency reaches 1 , it means the financing of enterprise is effective and achieves Pareto optimal state. When the financing efficiency value is in the range of 0.8 to 1 , enterprises located in the high financing efficiency interval, indicating that although enterprise has not reached the best financing efficiency value and is still not in the state of effective financing, the financing of enterprises has been used more reasonably. When the financing efficiency value is in the range of 0.5 to 0.8 , enterprises located in the relatively high financing efficiency interval, indicating that there is a relatively large gap for the enterprise to reach the effective financing and the enterprise fails to use the capital reasonably and effectively. When the financing efficiency value is less than 0.5 , it means that enterprises located in the low financing efficiency interval, the financing efficiency of enterprise is poor, and enterprises cannot effectively use the funds and need to reform and adjust themselves.

According to the DEA efficiency values that have been calculated for the sample of firms (overall technical efficiency, pure technical efficiency, and scale efficiency), this paper sorts out the efficiency index of 2008-2014 years and gets the overall situation of the financing efficiency of sample enterprises, as shown in Tables 6 and 7.

The market economy transition of China can be roughly divided into three periods: the spontaneous starting period 
TABLE 6: 2008-2014 industry distribution of comprehensive technical effective listed companies.

\begin{tabular}{lccccccc}
\hline \multirow{2}{*}{ Industry } & \multicolumn{7}{c}{ Number of firms } \\
& 2008 & 2009 & 2010 & 2011 & 2012 & 2013 & 2014 \\
\hline $\begin{array}{l}\text { Logistics industry } \\
\text { Technology hardware and }\end{array}$ & 4 & 2 & 2 & 3 & 2 & 4 & 4 \\
$\begin{array}{l}\text { equipment industry } \\
\text { Public utility industry }\end{array}$ & 3 & 3 & 3 & 4 & 3 & 5 & 5 \\
$\begin{array}{l}\text { Auto and auto parts } \\
\text { industry }\end{array}$ & 3 & 2 & 3 & 2 & 4 & 4 & 5 \\
$\begin{array}{l}\text { Energy industry } \\
\text { Biotechnology industry }\end{array}$ & 2 & 2 & 2 & 4 & 5 & 4 & 6 \\
$\begin{array}{l}\text { Durable goods and apparel } \\
\text { industry }\end{array}$ & 1 & 2 & 2 & 2 & 3 & 2 & 4 \\
Other industries & 3 & 4 & 2 & 5 & 3 & 1 & 2 \\
\hline Total & 23 & 25 & 22 & 28 & 27 & 30 & 39 \\
\hline
\end{tabular}

TABLE 7: 2008-2014 industry distribution of pure technical effective listed companies.

\begin{tabular}{lccccccc}
\hline \multirow{2}{*}{ Industry } & \multicolumn{7}{c}{ Number of firms } \\
& 2008 & 2009 & 2010 & 2011 & 2012 & 2013 & 2014 \\
\hline $\begin{array}{l}\text { Logistics industry } \\
\text { Technology hardware and }\end{array}$ & 3 & 3 & 5 & 4 & 6 & 6 & 8 \\
$\begin{array}{l}\text { equipment industry } \\
\text { Public utility industry }\end{array}$ & 5 & 6 & 7 & 6 & 6 & 7 & 8 \\
$\begin{array}{l}\text { Auto and auto parts } \\
\text { industry }\end{array}$ & 2 & 3 & 3 & 3 & 4 & 4 & 5 \\
$\begin{array}{l}\text { Energy industry } \\
\text { Biotechnology industry }\end{array}$ & 3 & 4 & 5 & 7 & 5 & 6 & 8 \\
$\begin{array}{l}\text { Durable goods and apparel } \\
\text { industry }\end{array}$ & 2 & 2 & 2 & 3 & 3 & 4 & 4 \\
Other industries & 4 & 6 & 7 & 8 & 5 & 4 & 5 \\
\hline Total & 31 & 37 & 39 & 44 & 40 & 43 & 56 \\
\hline
\end{tabular}

(1978-1991), the conscious moving-forward period (19922000) and the full acceleration period (2001-present). During the last period, Chinese government issued a series of key policies, and based on the timing of these policies the full acceleration period can be further divided into five subperiods: (1) the price hiking period (2004), during which measures of macroeconomic control and industry policies have been taken to decrease inflation and limit the expansion of heavy industries; (2) the industrial structure adjustment period (2006); (3) housing market adjustment period (2010), during which "six clauses" and "ten clauses" were put forward; (4) the period of supporting small businesses (2012); (5) the period after government recognizing the decisive role of the market in the allocation of resources (2014-present). In the following section, we will analyze the financing efficiency of 220 corporates according to the division of the aforesaid five subperiods.

Tables 6 and 7 show that in 2008, out of our sample of 220 listed firms, only 23 achieved both comprehensive technical efficiency and pure technical efficiency, accounting for $10.5 \%$ of our sample; 31 achieved pure technical efficiency alone, making up $14.1 \%$ of the sample; 8 achieved pure technical efficiency but not comprehensive technical efficiency, indicating that these firms' input to financing failed to reach scale efficiency and there may be excess of such input. The remaining 189 firms achieved neither comprehensive technical efficiency nor pure technical efficiency, meaning that there may be excess of input or lack of output and that these firms did not make the most of what they raise from the stock market. The findings correspond to the fact that the plight of China's stock market since 2001 has undermined listed firms' financing efficiency and the sustainability of the economic development. Besides, the implementation of the industry policy that limits the expansion of heavy industries hindered the development of heavy industries by adding to their financing difficulties, thus leading to the decrease of their financing efficiency indirectly.

25 firms achieved both comprehensive technical efficiency and pure technical efficiency, making up $11.36 \%$ of the total sample; of $16.8 \%$ of the sample, 37 firms achieved pure technical efficiency; 12 firms achieved pure technical efficiency but failed to achieve comprehensive technical efficiency, increasing by 4 more firms as compared with last year. The main causes of the improvement of the firms financing efficiency are that since 2006 China has gone through a very important period of industry structure transformation. During this period the government has vigorously supported the strategic emerging industries that are with huge potential, great knowledge-density, and lower energy consumption; those additional firms that have achieved comprehensive technical efficiency all have the characteristics of the strategic industries. In 2010 only 22 firms achieved both comprehensive technical efficiency and pure technical efficiency, making up $10 \%$ of the total sample; 39 firms achieved pure technical efficiency alone, making up $35.5 \%$ of the total sample; 17 firms achieved pure technical efficiency but failed to achieve comprehensive technical efficiency, increasing by 5 firms compared with 2009. The main reason for the changes is that since 2010, China's housing market has stepped into a period of adjustment and that 33 out of the whole 220 firms in the sample were from the real estate sector, making up $15 \%$ of the total sample, which led the listed firms' financing efficiency to decline on the whole in 2010. Only 28 firms achieved both comprehensive technical efficiency and pure technical efficiency in 2011, making up $12.7 \%$ of the total sample; 44 firms achieved pure technical efficiency, making up $20 \%$ of the sample that leaves 16 firms that achieved pure technical efficiency but failed to achieve comprehensive efficiency. The reason for the firms' increase in financing efficiency is that in 2011 the Chinese stock market was in a digestion period for the previous policies and that most firms have taken some counter measures and become accustomed to these policies. In 2012 only 27 firms achieved both comprehensive technical efficiency and pure technical efficiency, making up $12.27 \%$ of the total sample; 40 firms achieved pure technical efficiency, making up $18.2 \%$ of the total sample; 13 firms achieved pure technical efficiency but failed to achieve comprehensive technical efficiency. The number of firms that achieved either comprehensive technical efficiency or pure 
technical efficiency declined in 2012, because our sample was made up of listed firms that were the leading companies in each sector, and the Chinese government's policy in that time was to encourage the development of small businesses through the state-owned banking system. Hence the stock market's financing efficiency declined. In 2013 only 30 firms achieved both comprehensive technical efficiency and pure technical efficiency, making up $13.6 \%$ of the sample; 43 firms achieved pure technical efficiency, making up $19.5 \%$ of the sample; 13 firms achieved pure technical efficiency but not comprehensive efficiency. In 2014, only 39 firms achieved both comprehensive efficiency and pure technical efficiency, making up $17.7 \%$ of the sample; 56 firms achieved pure technical efficiency, making up $25.5 \%$ of the sample; 17 firms achieved pure technical efficiency but not comprehensive efficiency. The year 2014 has seen that China stepped into the period of market economy dominance, which made the firm's financing efficiency more dependent on its own market power and strength, and that led to the rise in the sample firms' financing efficiency.

The last 7 years' data reveals that among 24 industries, the firms with higher financing efficiency mainly come from daily consumer goods industry, optional consumer goods industry, and public utilities. More precisely, they are from the following seven sectors: logistics, technology hardware, and equipment; public utilities; auto and auto parts; energy; biotechnology; durable goods; and apparel industry. The reasons are as follows: China's consumption structure has upgraded into the rapid advancing stage, and consumers' demand for more high-quality goods is ever increasing; besides, the abovementioned sectors have received considerable amounts of subsidy from the government. Thus firms from these sectors are at an advantageous point to utilize its own resources and the market mechanism to increase its financing efficiency. And because of that, these sectors will become the leading force of China's economic development and continue to play a significant role in the future. Measures should be taken to promote the development of these sectors because they resemble the characteristics of strategic emerging industries.

It can be seen in the early stages of economic transformation that the efficiency of the equity financing of listed firms in China was generally low, and the majority of them had the inclination of blind expansion of scales, resulting in lower effectiveness of shareholders' investment. In addition, the higher proportion of state-owned shares will also have an adverse effect on the financing efficiency of China's listed companies [22]. As China transformed from a planned economy to a market economy and together with the industrial structure upgrading, the government gradually reduced the level of intervention in the economy, making the market power of the invisible hand gradually increase. In some sectors with higher degree of market dominance, the level of financing efficiency of firms becomes more and more dependent on the market and their own integrated development strength. In addition, as we can see from the development situation of China's listed companies, they should aim to improve the quality and efficiency and enhance the vitality of innovation by strengthening scientific and technological innovation, which can help to promote further economic transition [23].

It is noteworthy that in the economic transformation, China's equity financing market is still dominated by stateowned banking system and indirect financing. Although government-led financing system effectively opened up the financing channels for firms and provided huge financial support for the state-owned firms, it was essential for the long-term development of state-owned firms and macro economy. However, this financing system did not coordinate the development of economy in that the financing capacity of the financial market could not meet the needs of the real economy development. Structural defects in the system of financing, institutional defects, and functional defects were largely responsible for financing inefficient [24].

3.5. Projection Analysis. The nature of the evaluation of the decision-making units' (DMUs) relative effectiveness in Data Envelopment Analysis is to determine whether it is on the production frontier in the production possibilities set. If a DMU is non-DEA efficient, one can make it effective by adjusting the original input vector and the output vector, whose point after adjustment is its "projection" in the production frontier. Based on the comparative analysis of firms' efficiencies above, in this part projection theorem will be used to analyze the input and output variables of each DMU, in order to come up with appropriate measures for improvement. Among them, the target improvement of the input, output variables of non-DEA efficient firms is shown in Table 8.

As can be seen from Table 8, during the period of 20082014, the 220 listed firms in the sample generally have high equity value, equity concentration, and debt to assets ratio. The overvalued equity, high concentration of equity, and large-scale liabilities of listed companies pose serious problems of waste. Additionally, firms generally have low ROE and EPS, suggesting a lack of output and potential for future growth.

\section{Analysis of the Total Factor Productivity of China's Stock Market 2003-2014}

4.1. Introduction to Malmquist Model. The Malmquist method based on DEA can be used to calculate DMU's timevarying technical efficiency and total factor productivity (TFP). We use the same notation aforementioned: let $\mathbf{X}=\left(x_{1 t}, x_{2 t}, \ldots, x_{n t}\right)$ be the input vector and $\mathbf{Y}=\left(y_{1 t}\right.$, $\left.y_{2 t}, \ldots, y_{m t}\right)$ the output vector. The subscript " $t$ " indicates that both the input and output variables are time-varying. An output distance function of period $t$ can be defined as

$$
d_{t}\left(x_{t}, y_{t}\right)=\inf \left\{\theta_{t}:\left(x_{t}, y_{t} \mid \theta_{t}\right) \in P\left(x_{t}\right)\right\}
$$

where $P\left(x_{t}\right)$ is the production possibility frontier and $\theta_{t} \epsilon[0,1]$ the distance between an output vector and the DEA frontier under the assumption of constant return to scales.

To model the output-based Malmquist productivity change index we have two alternative approaches: measuring the productivity of the production point $\left(x_{t+1}, y_{t+1}\right)$ relative to 
TABLE 8: 2008-2014 sample firms' projection target (on average).

\begin{tabular}{|c|c|c|c|}
\hline Year & Variable & Radical movement (on average) & Slack movement (on average) \\
\hline \multirow{5}{*}{2008} & Equity value & -14836078554 & -6592256410 \\
\hline & Equity concentration & -11.16 & 20.31 \\
\hline & Debt to assets ratio & -26.26 & 0 \\
\hline & Rate of return on common stockholders' equity (ROE) & 25.05 & 0 \\
\hline & Earnings per share (EPS) & 0 & 13.75 \\
\hline \multirow{5}{*}{2009} & Equity value & -26721446619 & -17757163590 \\
\hline & Equity concentration & -33.69 & 14.93 \\
\hline & Debt to assets ratio & -27.783012 & -14.1940315 \\
\hline & Rate of return on common stockholders' equity (ROE) & 0 & 12.4 \\
\hline & Earnings per share (EPS) & 0 & 13.2 \\
\hline \multirow{5}{*}{2010} & Equity value & -4184218 & -28533851660 \\
\hline & Equity concentration & -14.7 & -15.61 \\
\hline & Debt to assets ratio & -13.74 & -16.5 \\
\hline & Rate of return on common stockholders' equity (ROE) & 16.92 & 13.43 \\
\hline & Earnings per Share (EPS) & 0 & 20.47 \\
\hline \multirow{5}{*}{2011} & Equity value & -12781546988 & -14037515163 \\
\hline & Equity concentration & -23.146 & -19.06 \\
\hline & Debt to assets ratio & 7.33 & 0 \\
\hline & Rate of return on common stockholders' equity (ROE) & 2.74 & 7.36 \\
\hline & Earnings per share (EPS) & 0 & 9.65 \\
\hline \multirow{5}{*}{2012} & Equity value & -5815789891 & 1882011799 \\
\hline & Equity concentration & -26.97 & 63.70 \\
\hline & Debt to assets ratio & -12.46 & -17.10 \\
\hline & Rate of return on common stockholders' equity (ROE) & 14.01 & 17.27 \\
\hline & Earnings per share (EPS) & 17.9 & 11.25 \\
\hline \multirow{5}{*}{2013} & Equity value & -20760421263 & -7056286009 \\
\hline & Equity concentration & -23.91 & 16.8 \\
\hline & Debt to assets ratio & -19.02 & -10.29 \\
\hline & Rate of return on common stockholders' equity (ROE) & 11.04 & 29.713 \\
\hline & Earnings per share (EPS) & 16 & 18.1 \\
\hline \multirow{5}{*}{2014} & Equity value & -32387016999 & -13696692148 \\
\hline & Equity concentration & -23.85 & -16.26 \\
\hline & Debt to assets ratio & -17.23 & -5.91 \\
\hline & Rate of return on common stockholders' equity (ROE) & 17.3 & 12.6 \\
\hline & Earnings per share (EPS) & 0.058 & 14.34 \\
\hline
\end{tabular}

the production point $\left(x_{t}, y_{t}\right)$ either based on the technology of period $t$ or based on the technology of period $t+1$. In order to avoid the choosing bias, we follow the method proposed by Färe and Zhang [25] and construct the Malmquist productivity change index as follows:

$$
\begin{aligned}
M & \left(x_{t+1}, y_{t+1}, x_{t}, y_{t}\right) \\
& =\left[\frac{d_{t}\left(x_{t+1}, y_{t+1}\right)}{d_{t}\left(x_{t}, y_{t}\right)} * \frac{d_{t+1}\left(x_{t+1}, y_{t+1}\right)}{d_{t+1}\left(x_{t}, y_{t}\right)}\right]^{1 / 2} .
\end{aligned}
$$

A value greater than 1 indicates positive TFP growth from period $t$ to period $t+1$. This index is, as we can see, the geometric mean of two Malmquist TFP indices, one using the technology of period $t$ and the other period $t+1$.

To calculate the above equation, the four component distance functions need to be calculated, which can be transformed to $4 \mathrm{LP}$ problems as follows:

$$
\begin{aligned}
& d_{t}\left(x_{t}, y_{t}\right)^{-1}=\max _{\phi, \lambda} \phi, \\
& \text { s.t. }-\phi y_{i t}+Y_{t} \lambda \geq 0, \\
& x_{i t}-X_{t} \lambda \leq 0 \text {, } \\
& \lambda \geq 0 \text {, } \\
& d_{t+1}\left(x_{t+1}, y_{t+1}\right)^{-1}=\max _{\phi, \lambda} \phi \text {, }
\end{aligned}
$$




$$
\begin{aligned}
\text { s.t. } & -\phi y_{i t+1}+Y_{t+1} \lambda \geq 0, \\
& x_{i t+1}-X_{t+1} \lambda \leq 0, \\
& \lambda \geq 0, \\
d_{t}\left(x_{t+1}, y_{t+1}\right)^{-1}=\max _{\phi, \lambda} \quad & \phi, \\
\text { s.t. } \quad & -\phi y_{i t+1}+Y_{t} \lambda \geq 0, \\
& x_{i t+1}-X_{t} \lambda \leq 0, \\
& \lambda \geq 0, \\
d_{t+1}\left(x_{t}, y_{t}\right)^{-1}=\max _{\phi, \lambda} \quad & \phi, \\
\text { s.t. } \quad & -\phi y_{i t}+Y_{t+1} \lambda \geq 0, \\
& x_{i t}-X_{t+1} \lambda \leq 0, \\
& \lambda \geq 0 .
\end{aligned}
$$

4.2. The Construction of Evaluation Index System. In this part we will use the aforesaid method to calculate the total factor productivity of China's stock market between 2003 and 2014 and analyze its trend. This part will focus on the whole stock market and treat it as a decision-making unit (DMU), instead of focusing on individual firm's financing efficiency; therefore the selection of the input and output variables will be different. Based on previous literature, we will look into the factors that affect the financing efficiency of China's stock market from three perspectives. (1) The institutional level, namely, the way of issuing and auditing new stocks, the pricing of IPO stocks; in this paper, the transaction cost of IPO stocks is our main concern. (2) The macroeconomic situation: research has shown and it has been proven in reality that the macroeconomic situation had a significant effect on the financing efficiency of a country's stock market. When the economy is in a boom phase, due to the expansion of business investment and hence higher financing needs, more firms want to raise money in the stock market, and investors are willing to put their money in because of an expectation of continued economic development; when the economy is in recession, firms cut their production plan, and that compresses financing needs; meanwhile investors no longer wish to participate in the stock market for a change of anticipation. (3) The level of activity in the stock market: the level of activity in the secondary market has a significant impact on the efficiency of the stock market financing. If there is no active secondary market, the initial offering of shares of listed companies will be flops.

\subsubsection{The Construction of Index System and Selection of Sample}

\section{(A) Input Variables}

(1) Number of Listed Firms. Number of listed firms can be viewed as a proxy variable to reveal the institutional factors
TABLE 9: Correlation matrix of input variables.

\begin{tabular}{lccc}
\hline & $\begin{array}{r}\text { Number of } \\
\text { listed firms }\end{array}$ & GDP & $\begin{array}{c}\text { Average turnover } \\
\text { of stocks }\end{array}$ \\
\hline $\begin{array}{l}\text { Number of listed firms } \\
\text { GDP }\end{array}$ & 1 & 0.9863 & -0.5616 \\
$\begin{array}{l}\text { Average turnover of } \\
\text { stocks }\end{array}$ & -0.5663 & 1 & -0.4798 \\
\hline
\end{tabular}

which influence the development of stock market. Along with the gradual deepening of economic restructuring, the regulatory focus of the capital market will also transform from the traditional way of prior approval to regulation in process and afterwards. The number of listed firms in China's stock market is expected to grow rapidly in the near future.

(2) GDP. This indicator reflects the impact of the macroeconomic situation on the stock market financing efficiency.

(3) Average Turnover of Stocks. This indicator reflects the activeness of the stock market:

$$
\text { Average turnover }=\frac{\text { Volume of trade in a year }}{\text { Total number of shares issued }} .
$$

(B) Output Variables. The output variables should reflect the efficiency of raising money in the stock market.

(1) Total Revenue Raised through the Stock Market. This variable directly reflects the financing effect of the stock market. One of firms' primary intention of going public is to raise funds. The total revenue raised through the IPO, share placement, and the issuance of convertible bonds to refinance is a direct reflection of the listed firms' financing efficiency of the year.

(2) The Shanghai Composite Index. Shanghai Composite Index, referred to as "the Shanghai index," has more than 1000 stocks in its sample in 2015. It is China's most representative stock price index.

The rise and fall of the Shanghai Composite Index may reflect the trends of the entire stock market.

4.2.2. Correlation Test of Variables. When using DEA to calculate the relative efficiency of DMUs, it is required that there exists no correlation or poor correlation among input variables or output variables and that the input and output variables are highly correlated. We use SAS software to calculate the correlation between the variables index, and the results are shown in Table 9.

As can be seen from Table 9, the correlation coefficient between GDP and the number of listed firms is 0.9863 , the correlation coefficient between the number of listed firms and average turnover of stocks is -0.5616 , the correlation coefficient between GDP and average turnover of stocks is -0.4798 . There is a strong correlation between the two input variables, the number of listed firms, and the GDP of the two input indicators. Because the correlation between the input 
TABLE 10: Results of principal component analysis.

\begin{tabular}{lcc}
\hline Input variables & Component 1 & Component 2 \\
\hline Number of listed firms & 0.631780 & 0.272481 \\
GDP & 0.615486 & 0.392750 \\
Average turnover of stocks & -0.471201 & 0.878352 \\
\hline
\end{tabular}

TABLE 11: TFP of China's stock market from 2004 to 2014.

\begin{tabular}{cccccc}
\hline Year & $\begin{array}{c}\text { Comprehensive } \\
\text { technical } \\
\text { efficiency }\end{array}$ & $\begin{array}{c}\text { Technical } \\
\text { change }\end{array}$ & $\begin{array}{c}\text { Pure } \\
\text { technical } \\
\text { efficiency }\end{array}$ & $\begin{array}{c}\text { Scale } \\
\text { efficiency }\end{array}$ & $\begin{array}{c}\text { Total factor } \\
\text { productivity } \\
\text { (TFP) }\end{array}$ \\
\hline 2004 & 1 & 0.797 & 1 & 1 & 0.797 \\
2005 & 1 & 0.515 & 1 & 1 & 0.515 \\
2006 & 1 & 3.434 & 1 & 1 & 3.434 \\
2007 & 1 & 2.075 & 1 & 1 & 2.075 \\
2008 & 13 & 0.334 & 1 & 1 & 0.334 \\
2009 & 1 & 1.563 & 1 & 1 & 1.563 \\
2010 & 1 & 1.05 & 1 & 1 & 1.05 \\
2011 & 1 & 0.607 & 1 & 1 & 0.607 \\
2012 & 1 & 0.855 & 1 & 1 & 0.855 \\
2013 & 1 & 0.965 & 1 & 1 & 0.965 \\
2014 & 1 & 1.246 & 1 & 1 & 1.246 \\
\hline
\end{tabular}

indicators will affect the results of DEA, before performing DEA analysis we use principal component analysis to extract the main ingredient. Using SAS.2 software to perform principal component analysis of the three input variables, the results are shown in Table 10. As can be seen, the first two principal components can explain $99.7 \%$ of the raw data.

As can be seen from Table 10, the first principal component was positively correlated with the number of listed firms and GDP and was negatively correlated with the average turnover of stocks, in which the number of listed firms and GDP weights higher and almost the same. Hence the first principal component mainly reflects GDP and the number of listed firms, revealing the macroeconomic situation and the impact of institutional factors. The second principal component is positively correlated with all three input variables, in which the average turnover of stocks accounts for more than $85 \%$, so the second principal component reflects the level of activity in the secondary market. The principal components are irrelevant or weakly relevant, using principal components as input variables and output variables will draw the correct and effective results.

4.3. DEA Results. Using DEAP 2.1 software for processing and the data from the previous principal component analysis, we obtain the Malmquist TFP index of China's stock market from 2004 to 2014, as can be seen from Table 11.

As can be seen from the last column of Table 11, the TFP growth of China's stock market is very rapid in 2006 and 2007 , and in 2008 it fell by nearly $70 \%$. This is mainly due to the 2008 economic crisis that originated in the US subprime mortgage loss. The amount of funds raised in the stock market and stock prices both dropped significantly. In order to make

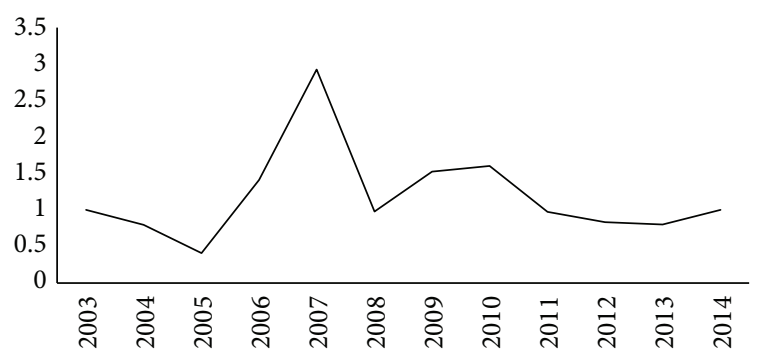

FIgURE 2: TFP of China's stock market from 2003 to 2014.

the results more clear, we set the TFP of China's stock market in 2003 to 1 and draw the TFP curve of China's stock market, as shown in Figure 2.

As can be seen from Figure 1, the TFP of China's stock market continued to decline from 2003 to 2005 and started to rise rapidly since then. The year 2005 has seen the start of state-owned shares reform, which initiates the transition from a government-oriented development to a market-oriented one. From 2005 to 2007 China’s stock market developed rapidly; on the one hand the average turnover of stocks and the Shanghai Composite Index rose rapidly, reflecting active trading in the secondary market and fastrising stock prices; on the other hand, the amount of funds raised by listed firms in the stock market rose from 339 billion yuan in 2005 to 789.8 billion yuan in 2007 .

However, starting in 2008, just as China's stock market was in the stage of rapid development, the economic crisis that originated in the US subprime mortgage loss quickly spread to China's capital market, causing serious impact on China's stock market. The TFP of China's stock market plunged from 2.92 in 2007 to 0.97 in 2008 . From 2008 to 2014 the TFP experienced first a rapid rise and then a rapid decline.

In 2007 TFP reached its highest level, 2.92 times that in 2003. However, in 2008 it dropped by $70 \%$ and rebounded slightly afterwards, but in 2014 the TFP of the stock market basically returned to the level in 2003.

In short, China's stock market is still in the development stage. Since China implemented the state-owned share reform in 2005, China's stock market began to develop very fast; in the future with the further economic transformation and upgrading of economic structure, China's stock market needs more reform. On the one hand, regulators should do a better job in risk management and hold the bottom line to prevent the occurrence of systemic risk; on the other hand regulators should put forward the registration system and further promote the activeness of the market.

\section{Conclusion and Suggestions}

From the analysis of the 220 listed firms' financing efficiency during 2008-2014, we can see the efficiency of the equity financing of listed firms in China is generally low, and total factor productivity of China's stock market continued to decline in 2003-2005 and then rose rapidly after 2005. In the light of the pattern, this paper makes several policy suggestions as follows. 
5.1. Complete the Issuing System for New Stocks to Further Animate the Market. China should accelerate the transformation from the approval system to the registration system, making it more suitable to the market demand. At this stage when the registration system is not yet implemented, the transparency of the approval process should be improved, so that investors and firms will have more faith and the financing efficiency will be improved as well [26].

5.2. Improve the Information Disclosure System and Stabilize Market Confidence. China's stock market has a very obvious feature and that is the presence of a strong "herding effect" [27]. The regulatory authorities should improve the information disclosure system, enhance supervision of listed firms to improve their information disclosure system, and build on the credibility of the regulators so that should anxiety occur regulators can release authoritative information to appease the market.

5.3. Optimize the Financing Structure. The financing structure refers to the proportion of internal financing, debt financing, and equity financing [28]. Enterprises should choose financing mode suitable for growth cycle. For example, in the initial stage, enterprise should pay attention to the accumulation of internal financing to reduce the cost of financing. In the growth stage, enterprise scale is continually expanding; they should be reasonable to choose debt financing and equity financing, adjust financing structure timely to reduce financing cost and financing risk, optimize financing structure, and improve the financing efficiency.

\subsection{Improve Risk Management Mechanism to Avoid Financial} Risks. The 2008 global financial crisis made huge impact on China's stock market. In the future, China's stock market must always pay attention to risk management, do a good job in investors' education, vigorously develop institutional investors, and strengthen the efficiency of supervision of listed firms [29].

5.5. Develop the Core Competence of the Enterprise and Enhance the Development Ability of the Listed Company. Under the support of the existing policy, the listed companies should increase R\&D investment and carry out research and development activities. The empirical study proves that the technical innovation index of listed companies in our country has a lot of room for growth; lack of capital investment or lack of technological innovation caused by capital investment result in low financing efficiency of China's listed companies [28]. Science and technology is the first productive force. Listed companies should establish a strong sense of innovation and constantly develop new products in order to provide innovative service concepts for the traditional industries.

\section{Competing Interests}

The authors (Ji-chang Dong, Lin-lin Zhu, Bing Wang, Zhi Dong, and Xiu-ting Li) declare that there is no conflict of interests regarding the publication of this paper.

\section{Acknowledgments}

The authors would like to thank the financial support of the project of National Natural Science Foundation of China (no. 71173213 , no. 71203217 , and no. 71403260) and the project of China Postdoctoral Science Foundation (no. 2013M540129).

\section{References}

[1] R. M. Stulz, "Managerial discretion and optimal financing policies," Journal of Financial Economics, vol. 26, no. 1, pp. 3-27, 1990.

[2] U. Schmidt-Mohr, "Rationing versus collateralization in competitive and monopolistic credit markets with asymmetric information," European Economic Review, vol. 41, no. 7, pp. 13211342, 1997.

[3] W. N. Chamberlain, "Conflict management in the entrepreneurventure capitalist relationship: an international comparative study," Working Paper, Northwestern School of Low of Lewis \& Clalk College and Helsinki University of Technology, 2009.

[4] C. A. Romano, G. A. Tanewski, and K. X. Smyrnios, "Capital structure decision making: a model for family business," Journal of Business Venturing, vol. 16, no. 3, pp. 285-310, 2001.

[5] V. Sulla, V. Sarria-Allende, and L. Klapper, "Small and medium size enterprise financing in Eastern Europe. Theory of investment," American Economic Review, no. 6, pp. 459-487, 2003.

[6] C. Cardone, M.-J. Casasola, and M. Samartín, "Do banking relationships improve credit conditions for Spanish SMEs," Business Economic Working Papers 05-28, 2005.

[7] Z. Kangling, "How should we view direct financing and indirect financing," Journal of Financial Research, no. 10, pp. 31-33, 1993.

[8] S. Wenbing, "Several issues need to be clarified with regard to financing methods," Journal of Financial Research, no. 1, pp. 3441, 1998.

[9] L. Haihong, "Several issues regarding state-owned enterprises' financing efficiency and the banking crisis," Research on Financial and Economic Issues, no. 3, pp. 41-45, 2000.

[10] W. Minghua, Financing Efficiency, Financing Institution, Banking Crisis, China Economic Publishing House, Beijing, China, 2000.

[11] N. Xinlan and H. Lianqin, "Theoretical framework of enterprise financing efficiency," Industrial Technology \& Economy, no. 10, pp. 157-159, 2010.

[12] Y. Quanxing, "Effect of listed Companies' financing structure," Accounting Research, no. 8, pp. 37-45, 2010.

[13] R. G. Rajan and L. Zingales, "What do we know about capital structure? Some evidence from international data," The Journal of Finance, vol. 50, no. 5, pp. 1421-1460, 1995.

[14] L. Lichang, "Listed Firm's financing efficiency based on DEA," Systems Engineering, vol. 22, no. 1, pp. 55-59, 2004.

[15] Y. Xiaowen, Comparative study on BRICS stock market growth [M.S. thesis], Shandong University of Finance and Economics, 2013.

[16] Y. Xiaobo, A comparative study on Chinese and Indian equity financing efficiency based on DEA [M.S. thesis], Shandong University of Finance and Economics, 2012.

[17] M. J. Farrell, “The measurement of productive efficiency," Journal of the Royal Statistical Society, Series A: General, vol. 120, no. 3, pp. 253-290, 1957. 
[18] C. Xiaojun, H. Shah, and W. Jie, "Discussion of listed firms' financing efficiency," Science and Technology Management Research, no. 3, pp. 231-233, 2007.

[19] Lv. Fan, The empirical study of the listed companies' financing efficiency on the small and medium enterprise board in China [M.S. thesis], 2010.

[20] M. Jesen, "The theory of the firm: managerial behavior, agency cost, and capital structure (Periodical style)," Journal of Financial Economics, vol. 3, pp. 64-78, 1976.

[21] Y. Yonghua, Analysis on financing mode and financing efficiency of small and medium sized enterprises in China [M.S. thesis], 2009.

[22] L. Shanyuan, Analysis of financing efficiency and ownership structure of listed companies in China [M.S. thesis], Southwestern University of Finance and Economics, 2007.

[23] W. Yiming, “The medium-term trend of China's economic growth and economic transformation," Macroeconomics, no. 11, pp. 3-13, 2013.

[24] Z. Yongming, "Innovative thinking of China's financing system innovation during economic transformation," Thinking Ideological Front, vol. 3, no. 2, pp. 115-116, 2008.

[25] R. Färe and Z. Zhang, "Productivity growth, technical progress, and efficiency change in industrialized countries," American Economic Review, vol. 84, no. 1, pp. 66-83, 1994.

[26] L. Xianghua and L. Enpu, "Research on the impact mechanism of stock market liquidity and macro economy," East China Economic Management, no. 8, pp. 97-104, 2013.

[27] W. Lirong, The contribution of stock market to economic growth-the empirical analysis in China [M.S. thesis], Xiamen University, 2006.

[28] W. Juan, The dynamic evaluation on the enterprise financing efficiency based on the DEA-Malmquist index model-taking the listed companies of high-tech small and medium enterprises as an example [M.S. thesis], Ocean University of China, Qingdao, China, 2012.

[29] Y. Xingmin and X. Jie, "A positive study of the relation between stock market and economic growth in China," Fudan Journal, vol. 4, no. 4, pp. 96-102, 2003. 


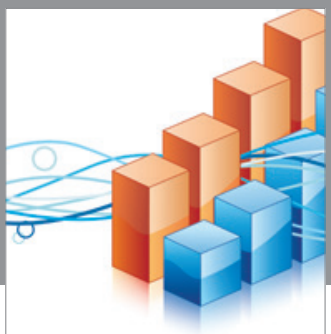

Advances in

Operations Research

vatem alat4

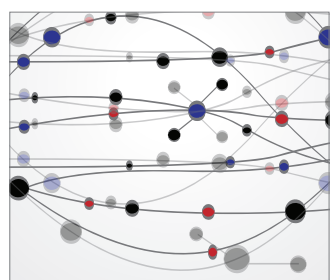

\section{The Scientific} World Journal
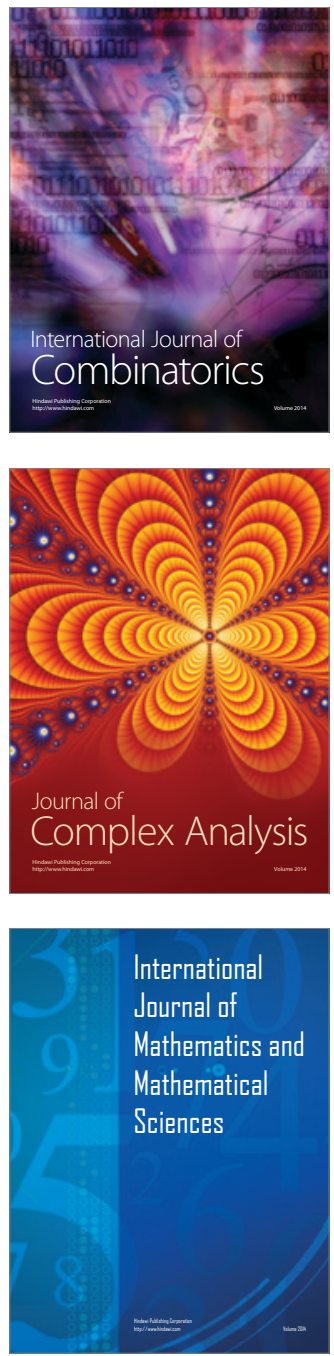
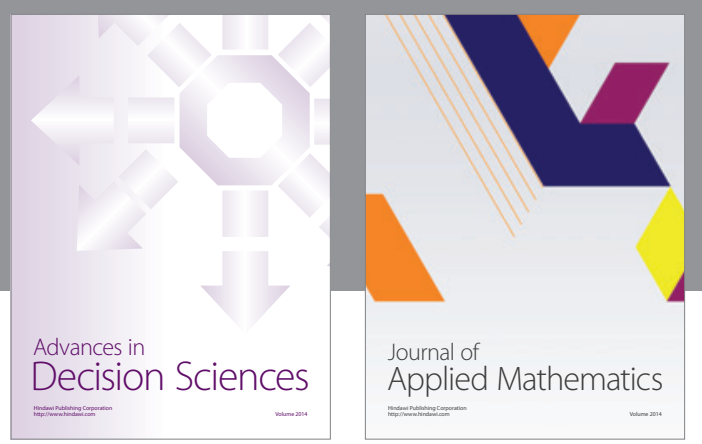

Algebra

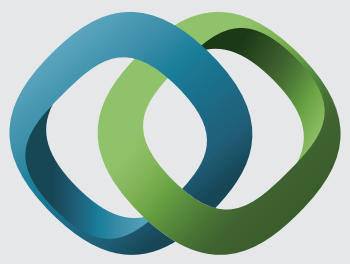

\section{Hindawi}

Submit your manuscripts at

http://www.hindawi.com
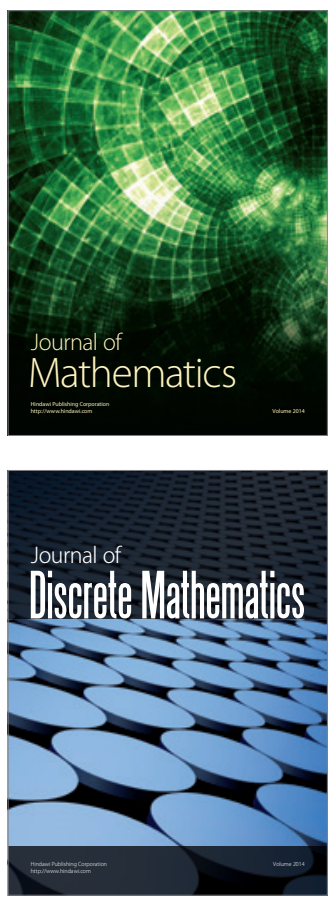

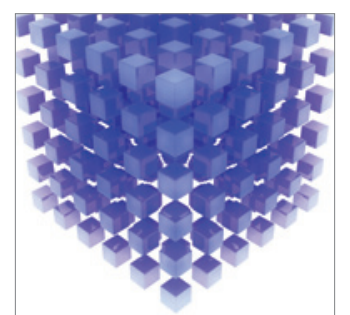

Mathematical Problems in Engineering
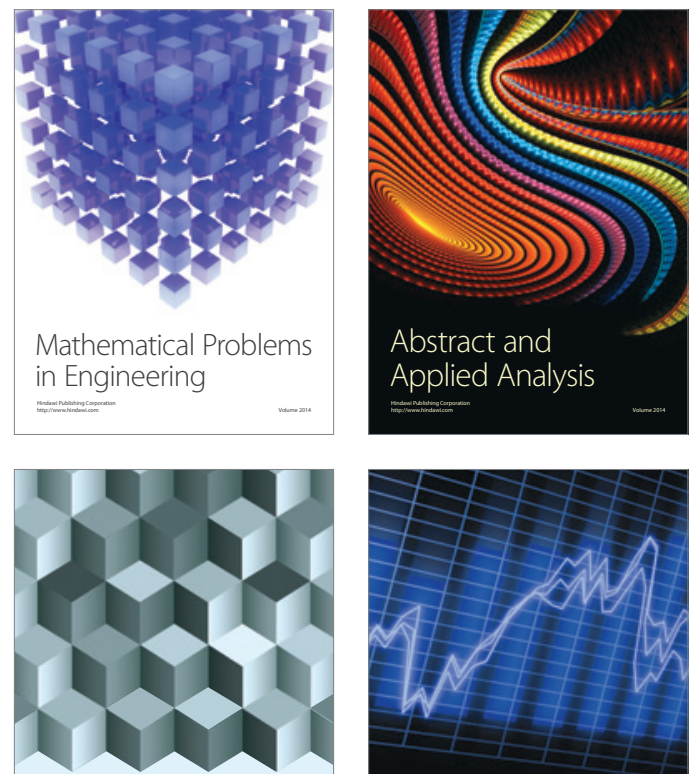

Journal of

Function Spaces

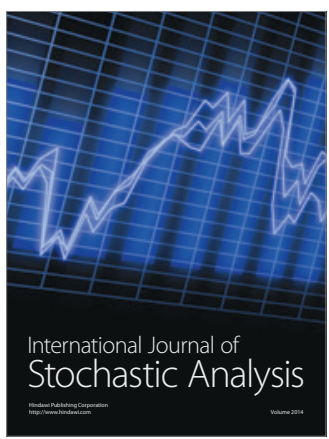

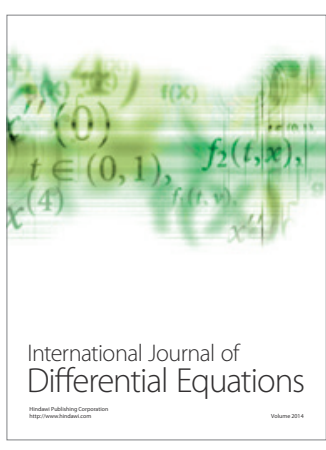
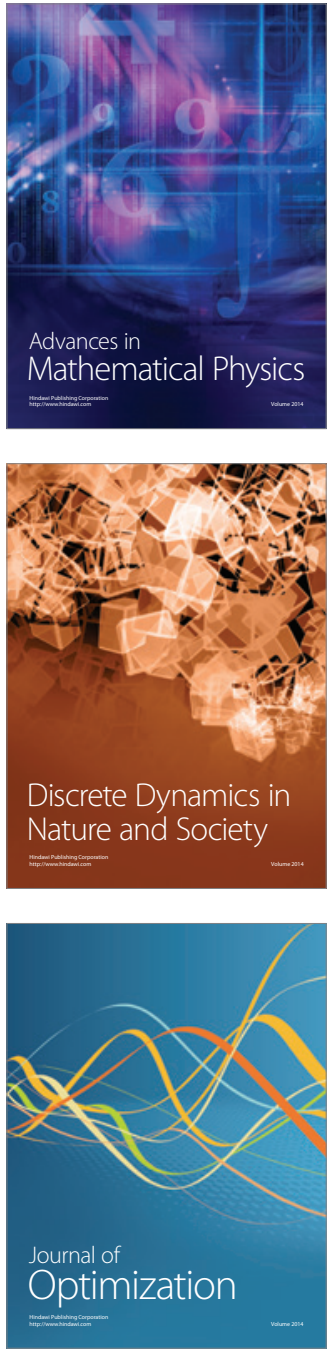